\title{
A Physical Model to Determine Snowfall over Land by Microwave Radiometry
}

\author{
G. Skofronick-Jackson ${ }^{(1)}$, M.-J. Kim ${ }^{(2)}$, J. A. Weinman ${ }^{(1,2)}$, D.-E. Chang ${ }^{(1,3)}$
}

1. Microwave Sensors Branch, NASA Goddard Space Flight Center, Greenbelt, MD

2. Department of Atmospheric Science, University of Washington, Box 351640

Seattle, WA 98195

3. Forecast Research Laboratory, Meteorological Research Institute, Korea Meteorological Administration, Seoul, 156-720, Korea

\section{Significant Findings}

This paper presents one of the first algorithms to estimate snow rate over land. This algorithm is unique with respect to the two other early empirical snowfall algorithms in that it is physically-based and relates hydrometeor properties to satellite-based passive millimeter-wave observations. This work relies on the Advanced Microwave Sounding Unit (AMSU-B) millimeter-wave $(89,150,183 \pm 1, \pm 3$, and $\pm 7 \mathrm{GHz}$ ) frequencies to observe the snow in the atmosphere. The higher frequencies are often advantageous because not only are they sensitive to frozen particles but they are also very sensitive to water vapor that obscures the highly variable underlying surface. In addition to snowfall rate, relative humidity profiles and fraction of ground covered by snow are also retrieved.

We found that the theory of scattering by randomly oriented dry snow particles at high microwave frequencies appears to be better described by regarding snow as a concatenation of "equivalent" solid ice spheres rather than as a sphere with the effective dielectric constant of an air-ice mixture. An equivalent sphere snow scattering model was validated against high frequency attenuation measurements. Satellite-based AMSU-B high frequency observations during the March 5-6, 2001 New England blizzard were used to retrieve snowfall over land. Vertical distributions of snow, temperature and relative humidity profiles were derived from the Pennsylvania State University-National Center for Atmospheric Research (PSU-NCAR) fifth-generation Mesoscale Model (MM5). Those data were applied and modified in a radiative transfer model that derived brightness temperatures consistent with the AMSU-B observations. The retrieved snowfall distribution was validated with radar reflectivity measurements obtained from the National Oceanic and Atmospheric Administration (NOAA) National Weather Service (NWS) ground-based radar network. 


\title{
A Physical Model to Determine Snowfall over Land by Microwave Radiometry
}

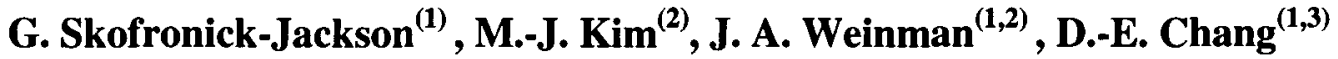

1. Microwave Sensors Branch, NASA Goddard Space Flight Center, Greenbelt, MD

2. Department of Atmospheric Science, University of Washington, Box 351640

Seattle, WA 98195

3. Forecast Research Laboratory, Meteorological Research Institute, Korea Meteorological Administration, Seoul, 156-720, Korea

\section{Popular Summary}

Although most global precipitation occurs as rainfall, snowfall plays a significant role in northern latitude hydrological cycles. One of the most important challenges for the future is to detect snowstorms from space. This study developed one of the first non-oceanic snowstorm estimation algorithms. Over land, the challenges are especially great: (1) satellite observations used for rainfall estimation are rather insensitive to frozen particles, (2) land surface characteristics can contaminate the observations, and (3) the relationships between the physical properties of frozen hydrometeors and passive brightness temperatures are not well understood. This work relies on millimeter-wave frequencies to observe the snow in the atmosphere. These frequencies are often advantageous because not only are they sensitive to frozen particles but they are also very sensitive to water vapor (almost always present in the atmosphere). Thus, they obscure the underlying surface by taking advantage of water vapor screening. This study presents a physical model of radiation from frozen particles at millimeter-wave frequencies that is used to infer snowfall rates over land. The retrieved snowfall rates are qualitatively validated against ground-based radar observations of the same March 5-6, 2001 New England Blizzard. 


\title{
A Physical Model to Determine Snowfall over Land by Microwave Radiometry
}

\author{
G. Skofronick-Jackson ${ }^{(1)}$, M.-J. Kim ${ }^{(2)}$, J. A. Weinman ${ }^{(1,2)}$, D.-E. Chang ${ }^{(1,3)}$
}

1. Microwave Sensors Branch

NASA Goddard Space Flight Center

Greenbelt, MD 20771

2. Department of Atmospheric Science

University of Washington, Box 351640

Seattle, WA 98195

3. Forecast Research Laboratory, Meteorological Research Institute

Korea Meteorological Administration,

Seoul, 156-720, Korea

Submitted to IEEE TGARS: June 27, 2003

\begin{abstract}
:
Because microwave brightness temperatures emitted by snow covered surfaces are highly variable, snowfall above such surfaces is difficult to observe using window channels that occur at low frequencies $(v<100 \mathrm{GHz})$. Furthermore, at frequencies $v \leq 37 \mathrm{GHz}$, sensitivity to liquid hydrometeors is dominant. These problems are mitigated at high frequencies $(v>100 \mathrm{GHz})$ where water vapor screens the surface emission and sensitivity to frozen hydrometeors is significant. However the scattering effect of snowfall in the atmosphere at those higher frequencies is also impacted by water vapor in the upper atmosphere. This work describes the methodology and results of physically-based retrievals of snow falling over land surfaces.

The theory of scattering by randomly oriented dry snow particles at high microwave frequencies appears to be better described by regarding snow as a concatenation of "equivalent" ice spheres rather than as a sphere with the effective dielectric constant of an air-ice mixture. An equivalent sphere snow scattering model was validated against high frequency attenuation measurements. Satellite-based high frequency observations from an Advanced Microwave Sounding Unit (AMSU-B) instrument during the March 5-6, 2001 New England blizzard were used to retrieve snowfall over land. Vertical distributions of snow, temperature and relative humidity profiles were derived from the Pennsylvania State University-National Center for Atmospheric Research (PSU-NCAR) fifth-generation Mesoscale Model (MM5). Those data were applied and modified in a radiative transfer model that derived brightness temperatures consistent with the AMSU-B observations. The retrieved snowfall distribution was validated with radar reflectivity measurements obtained from the National Oceanic and Atmospheric Administration (NOAA) National Weather Service (NWS) ground-based radar network.
\end{abstract}




\title{
A Physical Model to Determine Snowfall over Land by Microwave Radiometry
}

\author{
G. Skofronick-Jackson ${ }^{(1)}$, M.-J. Kim ${ }^{(2)}$, J. A. Weinman ${ }^{(1,2)}$, D.-E. Chang ${ }^{(1,3)}$
}

1. Microwave Sensors Branch

NASA Goddard Space Flight Center

Greenbelt, MD 20771

2. Department of Atmospheric Science

University of Washington, Box 351640

Seattle, WA 98195

3. Forecast Research Laboratory, Meteorological Research Institute

Korea Meteorological Administration,

Seoul, 156-720, Korea

Submitted to IEEE TGARS: June 27, 2003

\begin{abstract}
:
Because microwave brightness temperatures emitted by snow covered surfaces are highly variable, snowfall above such surfaces is difficult to observe using window channels that occur at low frequencies $(v<100 \mathrm{GHz}$ ). Furthermore, at frequencies $v \leq 37 \mathrm{GHz}$, sensitivity to liquid hydrometeors is dominant. These problems are mitigated at high frequencies $(v>100 \mathrm{GHz})$ where water vapor screens the surface emission and sensitivity to frozen hydrometeors is significant. However the scattering effect of snowfall in the atmosphere at those higher frequencies is also impacted by water vapor in the upper atmosphere. This work describes the methodology and results of physically-based retrievals of snow falling over land surfaces.

The theory of scattering by randomly oriented dry snow particles at high microwave frequencies appears to be better described by regarding snow as a concatenation of "equivalent" ice spheres rather than as a sphere with the effective dielectric constant of an air-ice mixture. An equivalent sphere snow scattering model was validated against high frequency attenuation measurements. Satellite-based high frequency observations from an Advanced Microwave Sounding Unit (AMSU-B) instrument during the March 5-6, 2001 New England blizzard were used to retrieve snowfall over land. Vertical distributions of snow, temperature and relative humidity profiles were derived from the Pennsylvania State University-National Center for Atmospheric Research (PSU-NCAR) fifth-generation Mesoscale Model (MM5). Those data were applied and modified in a radiative transfer model that derived brightness temperatures consistent with the AMSU-B observations. The retrieved snowfall distribution was validated with radar reflectivity measurements obtained from the National Oceanic and Atmospheric Administration (NOAA) National Weather Service (NWS) ground-based radar network.
\end{abstract}




\section{Introduction:}

Measurement of global precipitation is one of the goals of climate studies. Although most global precipitation occurs as rainfall, snowfall plays a significant role in the extra-tropical hydrological cycle. Snow, falling early in winter, can retard freezing of the underlying soil thereby allowing subsequent melt water to penetrate the ground. Conversely, if the ground freezes because snow falls late in winter, flooding may ensue from run-off during the spring thaw. Snow also serves as a reservoir of water that can be released later in the year to support agriculture and hydroelectric power generation. Snowstorms can also be hazardous for transportation and other economic activities. One of the most important challenges for future satellites is to detect snowstorms from space. This study presents a physical model of radiation at millimeter-wave frequencies that seeks to infer snowfall rates over land by taking advantage of water vapor screening to obscure the underlying snow-covered surface.

Mid-latitude precipitation occurs in a wide variety of forms from snow to drizzle to rain and to hail [1]. Storm types include multicell and supercell thunderstorms, extratropical cyclones and hurricanes. The well developed techniques to study tropical precipitation, using frequencies $\leq 90 \mathrm{GHz}$, addressed rain occurring in nearly moist adiabatic environments. Extratropical cyclones are a completely different setting for precipitation than any type of tropical storm. Broad zones of frontal lifting produce broad sheets of clouds and precipitation that are mostly though not completely stratiform. These stratiform precipitation regions are similar microphysically to the stratiform regions of tropical mesoscale convective systems. However the generally cooler conditions often produce a melting layer that is near the earth's surface. Under the coldest conditions, the precipitation reaches the surface as snow.

Most spaceborne remote sensing of snow has addressed the measurement of snow accumulation on the ground, see [2]. Snow within the atmosphere has only been derived from microwave radiometry over oceanic regions where the measurements were not affected by snow accumulated on the ground [3][6]. Furthermore, most of the snow considered in the above studies are frozen particles above the melting layer or anvil ice clouds, not snow falling at the surface. Because snow accumulation on land affects the emission properties of the surface, the measurement of snowfall within the atmosphere has been difficult with radiometers that operate at frequencies less than $100 \mathrm{GHz}$ where the atmosphere is relatively transparent and the sensitivity to frozen particles is lower than at higher frequencies. Snow falling over land has been derived from the brightness temperatures at frequencies where absorption occurs using empirical relationships by Kongoli et al. [7] and by Chen and Staelin [8]. Although such empirical relationships are operationally useful, physical models are needed to understand how the retrieved snowfall depends on the various ground and atmospheric factors that affect the measured brightness temperatures. To our knowledge, this is the first retrieval of snow falling over land based on a physical model.

The Advanced Microwave Sounding Units (AMSU-B) radiometers on the NOAA 15, 16, 17 spacecraft [9] have the channel set and resolution to resolve locally intense precipitation. The AMSU$B$ have $10 \times \sim 25 \mathrm{~km}$ footprints and provide observations at 89,150 and $183 \pm 1, \pm 3, \pm 7 \mathrm{GHz}$. These channels are sensitive to both the water vapor (for surface screening) and the snow particles. The AMSU-B radiometer on NOAA-15 initially encountered radio frequency interference from on-board 
transmitters that were ultimately shut down in the autumn of 1999 so that reliable spaceborne data at frequencies greater $100 \mathrm{GHz}$ were available by the winter of 2000-01. This study presents a physical model that was used to derive snowfall over land from AMSU-B observations.

\section{Case Study:}

The blizzard of 5-6 March 2001 presented a unique opportunity to observe intense snowfall over land. That blizzard was one of the more intense snow storms of the season, depositing on the order of $50 \mathrm{~cm}$ of snow on much of Vermont, New Hampshire and northeastern New York with several stations reporting that $75 \mathrm{~cm}$ were deposited for the day. Both the NOAA 15 and 16 satellites observed this blizzard (NOAA-17 was launched in June 2002). However, the best spatial and temporal coverage between available ground radar data and AMSU-B data was at 2300 UTC with the NOAA-15 AMSUB observations.

\subsection{Radar Data:}

Fig. 1a shows a composite of the National Weather Service (NWS) operational weather radar reflectivity, $Z_{\text {eff }}\left(\mathrm{mm}^{6} / \mathrm{m}^{3}\right)$ obtained from several ground stations over the Northeastern United States on 5 March 2001 at 23:00 UTC. Note that the limited range of the radar data does not extend far over the ocean area (Fig. 1a). The snowfall was greatest over Connecticut, Maine, Vermont, and New Hampshire. This composite of $Z_{\text {eff }}$ is based on whichever of the lowest four antenna elevations yield the highest reflectivity. At ranges beyond $50 \mathrm{~km}$ from the radar, those elevation angles are usually $0.5^{\circ}$. The heights at which those reflectivities are measured varies with distance from the particular radar, falling between 0.5 and $\sim 2.5 \mathrm{~km}$. Although the NWS operational radar data have well known limitations, in the absence of a preplanned field observation campaign, they provide readily available observations to compare to snowfall derived from microwave brightness temperatures.

The radar reflectivity data were smoothed with a $16 \times 16 \mathrm{~km}$ template to match the finest spatial resolution of the AMSU-B channels. The center points of the smoothed radar data matched those of the AMSU-B latitude and longitude center points for each footprint. Since the NWS radar reflectivity resolution is very fine however its latitude and longitude mapping was not precise (offsets by no more than 0.1 degrees). Averaging the NWS image to the AMSU-B resolution tended to smooth any effects of location mismatch. The maximum reflectivity in the smoothed radar reflectivity data over the land is $\sim 37 \mathrm{dBZ}$. Depending on the relationships used, this reflectivity can correspond to rain fall rates of up to $6.7 \mathrm{~mm} \mathrm{hr}^{-1}$ (or snowfall rates of $67 \mathrm{~mm} \mathrm{hr}^{-1}$ ).

\subsection{Microwave Data from AMSU-B:}

Brightness temperatures, $\mathrm{Tb}_{150}$, measured by the $150 \mathrm{GHz}$ channel of the NOAA-15 AMSU-B, at 2302 UTC 5 March 2001, are shown in Fig. 1b. Note the cold brightness temperatures $(<240 \mathrm{~K})$ in the blizzard region over Vermont and New Hampshire (near 42-44N, 71-74W), and the absence of contrast in surface features such as the Gulf of St. Lawrence (near $47 \mathrm{~N}, 72 \mathrm{~W}$ ) and the Great Lakes (near $44 \mathrm{~N}, 77 \mathrm{~W}$ ). This brightness temperature distribution is similar to the radar $Z_{\text {eff }}$ values shown in Fig 1a. Figs. 1c, d, e, and $\mathrm{f}$ show the distributions of the 89 and $183 \pm 7, \pm 3, \pm 1 \mathrm{GHz}$ brightness temperatures, $\left(\mathrm{Tb}_{89}, \mathrm{~Tb}_{183 \pm 7}, \mathrm{~Tb}_{183 \pm 3}\right.$ and $\mathrm{Tb}_{183 \pm 1}$, respectively) measured from AMSU-B at 2302 UTC 
on 5 March 2001. It can be seen in Fig. $1 \mathrm{c}$ that some of the cold $\mathrm{Tb}_{89}$ values scattered over Canada may have been caused by accumulated antecedent snow. At $89 \mathrm{GHz}$, it is difficult to distinguish snow in the atmosphere from snow on the ground. Note that the Great Lakes and the St. Lawrence River, that are evident in Fig. 1c, are screened by water vapor in the $183 \mathrm{GHz}$ channels in Figs. 1d, e, f. Although brightness temperatures are more affected by the water vapor profile, evidence of the snow still persists in the $183 \pm 3 \mathrm{GHz}$ channel. The $\mathrm{Tb}_{183 \pm 1}$ measurement reveals little indication of the blizzard, being mainly responsive to water vapor at altitudes above the heaviest precipitation. It should be noted that the core of the snowstorm is at about $35^{\circ}$ from nadir in the AMSU-B scanning pattern.

\section{Snow Retrieval Method:}

This study seeks to derive characteristics of snow whose electromagnetic properties are consistent with microwave brightness temperatures at several frequencies provided by the AMSU-B sensors. Brightness temperatures are computed from an Eddington approximation of the second kind. That radiative transfer model employs information generated from a six parameter model of the atmosphere associated with snow storms. Three of the six parameters are allowed to vary to generate different snow cloud and surface conditions, the other three parameters are set to fixed values based on statistics from a cloud resolving model and external measurements. It is expected that there are only 3-4 degrees of freedom in the five AMSU-B brightness temperature channels.

The first and second of the three variable parameters are used to adjust the distributions of the vertical structure of snow mass and relative humidity and are generated from the Pennsylvania State University-National Center for Atmospheric Research (PSU-NCAR) fifth-generation Mesoscale Model (MM5). During the retrieval the parameterized snow model profile mass is allowed to extend beyond the confines of the MM5 simulations. This is necessary because the maximum surface snow mass over land produced by MM5 was only $0.7 \mathrm{~g} \mathrm{~m}^{-3}$ corresponding to a lower reflectivity of $30 \mathrm{dBZ}$ than seen in Fig. 1a. Thus the retrieved profiles are not just weighted combinations of the MM5 profiles and they may vary more widely than the MM5 model profiles. The microphysical model of the falling snow also rests upon independent millimeter-wave attenuation measurements. The third adjustable parameter defines the fraction of snow ground cover and generates a composite surface emissivity using previously reported emissivities of snow and soil covered surfaces.

The three fixed parameters include height levels, temperature profiles, and snow size. These parameters, along with the variable parameters, produce snow cloud characteristics used to generate a database of brightness temperatures that would be observed at the AMSU-B frequencies using forward radiative transfer calculations. The optimal estimate of the snow parameters is derived from the best match between computed and measured brightness temperatures at all AMSU-B frequencies.

Snowfall mass distributions are derived by matching measured brightness temperatures to those derived from radiative transfer models applied to MM5 temperature and adjusted humidity profiles. The snowfall in the retrieval model is represented by equivalent spheres whose diameters are of the same order of magnitude as those needed to model attenuation measured during previous field experiments. Finally the retrieved snowfall is compared to the radar reflectivity measurements provided by the NWS operational radars to estimate the validity of the retrieval. 


\subsection{MM5 Mesoscale Model:}

The MM5 model described by [10], [11] was used in this study. A description of the MM5 model used here was presented by Chang et al. [12]. The model domain was centered at $35^{\circ} \mathrm{N} \times 70^{\circ} \mathrm{W}$; it consisted of $100 \times 120$ grid points with $40 \mathrm{~km}$ separation. The simulation generated profiles of temperature, relative humidity, cloud water, rain, cloud ice, snow, hail, and graupel mass at each of the grid points in the volume of the model domain.

The MM5 model was initialized at 0000 UTC 5 March 2001, and model integration was performed for a period of $48 \mathrm{~h}$. The initial and boundary conditions for the experiment were obtained by interpolating the National Center for Environmental Prediction (NCEP) $2.5^{\circ} \times 2.5^{\circ}$ global analysis for 0000 UTC 5 March 2001 to the model grid points and then enhancing those with coincident rawinsonde soundings. The sea surface temperature data were also obtained from NCEP global analysis and were kept unchanged during the model integration. However, the land surface temperature was predicted using surface energy budget equations in which the effect of short and long wave radiation and cloud radiation were included.

Any rain erroneously generated over coastal regions by the MM5 simulation was assumed to be snow because all of the reported temperatures in those areas were below $-2^{\circ} \mathrm{C}$. The National Lightning Detection Network (NLDN) [13] observed some lightning off-shore, but not over New England. The cold land surface temperatures appeared unable to produce sufficient convection to produce lightning and perhaps graupel. Although not shown, the shape (but not the location) of the spatial distribution over land and ocean from the MM5 model compares well with that of the radar reflectivity, $Z_{\text {eff, }}$ shown in Fig. 1a.

\subsection{Snow Cloud Parameterization:}

Three fixed parameters in the retrieval include height levels, temperature profile, and snow size. The height levels and temperature profiles were set to fixed values provided in Table I. The temperature profiles were determined by the average of the MM5 temperature profiles over land. The variability of the MM5 temperature profiles over land is minimal (about $10 \mathrm{~K}$ at lower altitudes). The three variable parameters and the fixed snow size will be described in detail in the following sections.

\subsubsection{Relative Humidity Parameters}

Profiles of the relative humidity with respect to ice used in the retrieval were modified by adding a scaled addition to a minimum relative humidity profile generated by the MM5 over land. Those profiles were interpolated between the values cited in Table 1 to yield:

$$
\mathrm{RH}(\mathrm{z})=\mathrm{RH}_{\min }(\mathrm{z})+\Delta \mathrm{RH}(\mathrm{z}) \mathbf{r}
$$

where $\Delta \mathrm{RH}(\mathrm{z})=\mathrm{RH}_{\max }(\mathrm{z})-\mathrm{RH}_{\min }(\mathrm{z})$ is the maximum range of acceptable relative humidity values from MM5 and $z$ denotes the height. The adjustable relative humidity scaling parameter $\mathbf{r}$ ranges 
from 0.0 to 1.0 in 0.1 unit increments. The value of $\mathbf{r}$ was determined from the retrieval by minimizing the difference between observed and retrieval calculated brightness temperatures

Table I. Atmospheric parameters inferred from the MM5 model of the March 5-6, 2001 blizzard.

\begin{tabular}{|c|c|cc|c|}
\hline $\begin{array}{c}\text { Height } \\
(\mathrm{km})\end{array}$ & $\mathrm{T}$ & \multicolumn{2}{|c|}{$\mathrm{RH}(\%)$} & $\mathrm{M}(\mathrm{z})$, \\
& & $\mathrm{RH}_{\min }$ & $\Delta \mathrm{RH}$ & $\begin{array}{c}\text { Normalized } \\
\text { Snow Profile }\end{array}$ \\
\hline 0.02 & 267.50 & 80 & 20 & 1.00 \\
\hline 0.5 & 267.13 & 70 & 30 & 0.95 \\
\hline 1.0 & 266.75 & 60 & 40 & 0.90 \\
\hline 2.0 & 266.27 & 20 & 80 & 0.76 \\
\hline 3.0 & 265.23 & 11 & 89 & 0.61 \\
\hline 4.0 & 261.72 & 9 & 91 & 0.51 \\
\hline 5.0 & 255.77 & 6 & 94 & 0.35 \\
\hline 6.0 & 248.64 & 4 & 96 & 0.20 \\
\hline 8.0 & 232.51 & 2 & 98 & 0.06 \\
\hline 10.0 & 221.37 & 2 & 98 & 0 \\
\hline 12.0 & 222.52 & 2 & 34 & 0 \\
\hline 14.0 & 220.94 & 2 & 18 & 0 \\
\hline 16.0 & 216.61 & 2 & 16 & 0 \\
\hline
\end{tabular}

\subsubsection{Surface Emissivity Parameter}

The radiative transfer equation also requires knowledge of the emissivity of the variable surface features including accumulated snowfall. The boundary conditions were determined partially by the accumulated antecedent snow whose emissivities, $\boldsymbol{\varepsilon}_{\mathrm{s}}$, for deep dry snow at the relevant frequencies are obtained from [14]. Although [14] only measured emissivities to $150 \mathrm{GHz}$, they did provide curve fits for deep dry snow extending to $200 \mathrm{GHz}$. The $183 \mathrm{GHz}$ emissivity was extracted from these curve fits. The values of $\varepsilon_{\mathrm{s}}$ at a $53^{\circ}$ viewing angle are $0.64,0.724,0.8$ for 89,150 , and $183 \mathrm{GHz}$ respectively [14].

The emissivity used in the radiative transfer model is a weighted mean of the emissivity of snow cover, $\varepsilon_{\mathrm{s}}$, and that of $\varepsilon_{0}$. The $\varepsilon_{0}$ is an average of emissivities from bare soil, frozen soil, and winter forest/conifer and is 0.98 for all frequencies [15]. The effective emissivity is thus

$$
\varepsilon=f \varepsilon_{\mathrm{s}}+(1-f) \varepsilon_{\mathrm{o}}
$$

where $f$ is the fraction of the ground covered by snow and has 6 values: $0.0,0.2,0.4,0.6,0.8$, and 1.0. The parameter mostly affects the $89 \mathrm{GHz}$ brightness temperatures that permit the earth's surface to be seen through light precipitation. 


\subsubsection{Snow Mass Parameter}

Representative snow mass profiles were taken from the MM5 snowing profiles over land and normalized with respect to their surface snow mass, to obtain a normalized profile, $M(z)$, shown in Table 1. Note that we consider the surface snow mass to be the snow mass at $20 \mathrm{~m}$ above the surface (see Table 1). Since the MM5 snow profiles truncated to $0 \mathrm{~g} \mathrm{~m}^{-3}$ at a $10 \mathrm{~km}$ height, the $\mathrm{M}(\mathrm{z})$ profile has 0 mass at a $10 \mathrm{~km}$ height (See Table 1). Snow mass profiles used in the subsequent retrieval are scaled by a factor $\mathbf{m}$ in $\mathrm{g} \mathrm{m}^{-3}$. The snow mass scaling parameter $\mathbf{m}$ could assume 39 values: $0.0,0.02$, $0.065,0.1,0.2,0.4,0.6, \ldots, 6.8,7.0 \mathrm{~g} \mathrm{~m}^{-3}$. These values convert to surface melted snowfall rates ranging from 0 to $\sim 32 \mathrm{~mm} \mathrm{hr}^{-1}$, or equivalently, to reflectivities ranging from 0 to $\sim 48 \mathrm{dBZ}$. These snowfall rates, although beyond the surface maximum of $0.8 \mathrm{~g} \mathrm{~m}^{-3}$ given by the MM5 model, provide enough variability for the range of values seen in Fig. 1a. The snow mass content used in the retrievals is

$$
M_{s}(z)=\mathbf{m} \mathrm{M}(\mathrm{z}) .
$$

\subsubsection{Snow Size Parameter Selection}

The greatest challenge of snowfall studies is determining the electromagnetic properties of the wide variety of shapes and sizes of snowflakes. Microwave scattering and emission properties of hydrometeors depend on their size, shape, density, and whether they are frozen, melting or liquid. Wet snow and sleet were reported along the New England coast, but the mean temperatures encountered in New Hampshire and Vermont remained around $-5 \mathrm{C}$, and reported maxima were only $-2 \mathrm{C}$, we therefore disregarded melting over inland regions throughout the entire day. Furthermore, our case study observations are at 2300 UTC or 1900 local time when the temperatures are less than the daytime highs. Snow particles in this study were therefore regarded as dry containing no melt water.

We first assumed that the mass densities of the MM5 model consisted of large fluffy snow particle size distributions (i.e., $10 \%$ ice, $90 \%$ air) as suggested by Rutledge and Hobbs [16]. Effective medium mixing theories have been used by [5], [6], [17], [18] to represent the dielectric constant of snow at frequencies below $90 \mathrm{GHz}$ [19]. Using these models for the higher frequencies seemed to produce inappropriate electromagnetic characteristics. For example, the low density particles represented by effective medium mixing models did not provide enough scattering because the asymmetry factor was too large. Large asymmetry factors increased forward scattering of the radiation from the warm lower layers so that computed brightness temperatures were too warm. Although the finite difference time domain method [20] can be used to compute the scattering characteristics of non-spherical particles at any frequency the shape of the frozen crystal habit can only be crudely estimated, so that a simpler approach appears to be justified.

One such simpler approach is the procedure of Grenfell and Warren [21]. Grenfell and Warren (G-W) represented randomly oriented frozen particles as a concatenation of "equivalent" ice spheres whose effective diameter was determined by the ratio of the volume-to-surface-area, (V/A).

$$
D_{e f f}=6 \mathrm{~V} / \mathrm{A}
$$


The G-W procedure transforms inhomogeneous non-spherical (e.g., fluffy) ice particles into an ensemble of solid ice spheres; this greatly simplifies the determination of the scattering properties of the hydrometeors. Representing irregular particles as ensembles of equivalent spheres, has been used in the cirrus cloud infrared radiation modeling community and their properties have been analyzed by [22]-[23]. G-W demonstrated that equivalent spheres can adequately describe the transmittance and reflectance of diffuse infrared radiation through randomly oriented prisms. Moreover, [24] showed that the equivalent sphere approach accounts for the shape transition from needles to plates. It is noteworthy that such effective diameters are mainly determined by the small dimensions i.e., the thickness of large disks or the diameters of long cylinders (Eq. 3. in G-W) rather than the maximum dimensions that are most frequently measured.

The distributions of effective diameters, $D_{\text {eff }}(\mathrm{mm})$ based on the G-W model were represented by a Gamma function of order 1 .

$$
N\left(D_{e f f}\right)=N_{o} D_{e f f} \exp \left(-\Lambda_{\mathrm{GW}} D_{e f f}\right) .
$$

The $N_{0}$ is related to the G-W slope parameter $\Lambda_{\mathrm{GW}}$ and the snow mass density, $M_{s}\left(\mathrm{~g} \mathrm{~m}^{-3}\right)$ at each height, $z$ :

$$
M_{s}(z)=\frac{\pi \rho_{G W}}{6} \int_{0}^{\infty} N\left(D_{e f f}\right) D_{e f f}^{3} d D_{e f f}
$$

where $\rho_{\mathrm{GW}}=\rho_{\mathrm{i}}=0.917 \mathrm{~g} \mathrm{~m}^{-3}$ so that

$$
N_{0}=\frac{M_{s}(z) \Lambda_{G W}^{5}}{4 \pi \rho_{G W}}
$$

Note that the $N_{o}$ value varies with differing snow masses at each height, through Eqn. 7 and that the number of "equivalent" spheres is greater than the actual number of non-spherical scattering particles. The effective polydispersion diameter weighted over such a size distribution is:

$$
\left\langle D_{e f f}\right\rangle=\frac{4}{\Lambda_{G W}} .
$$

Once the G-W size distribution was specified, the effective diameter, $\left\langle D_{e f f}\right\rangle$ was determined by employing measurements obtained from other snow events to infer the attenuation coefficient (and hence $\left\langle D_{e f f}\right\rangle$ ) of snow to use in the electromagnetic scattering model. The size parameter $\left\langle D_{\text {eff }}\right\rangle$ was derived by applying Mie theory to compute the extinction coefficient, $k_{\text {Sext }}\left(\mathrm{km}^{-1}\right)$ of snow as a function of frequency, $v(\mathrm{GHz})$. The attenuation per mass is:

$$
\mathrm{A}\left(v, M_{s}\right)=10 \log _{10}(\mathrm{e}) k_{S e x t} / M_{s},
$$


Results of those calculations were compared to $\mathrm{A}\left(v, M_{s}\right)$ measured for several winter seasons for frequencies between 96 and $225 \mathrm{GHz}$ by [25], [26]. Fig. 2 compares the attenuation per mass as a function of frequency measured during the samples with curves generated by Mie theory for $\left\langle D_{\text {eff }}>\right.$ values of $0.1 \mathrm{~mm}$ and $0.06 \mathrm{~mm}$. It is well known that the crystal habit varies with height and that $\left\langle D_{\text {eff }}\right\rangle$ diminishes with height [4]. A simplification was invoked because it is difficult to justify the introduction of diverse shapes in the model in the absence of measurements. Thus snow particles were assumed to be spherical and to be represented by:

$$
\begin{aligned}
& <D_{\text {eff }}>=0.10 \mathrm{~mm} \quad \text { for } 0.0<z<0.5 \mathrm{~km} \\
& =0.06 \mathrm{~mm} \text { for } 0.5<z<10.0 \mathrm{~km} \text {. }
\end{aligned}
$$

These dimensions are characteristic of the small crystal dimensions, i.e. the thickness of plates or diameters of needles [27], [28]. Furthermore, the $\left\langle D_{e f f}\right\rangle=0.1 \mathrm{~mm}$ below $0.5 \mathrm{~km}$ better matched the ground-based observations of Nemarich et al. [25] and Wallace [26], while the $\left\langle D_{\text {eff }}\right\rangle=0.06 \mathrm{~mm}$ above $0.5 \mathrm{~km}$ yielded brightness temperatures that best match the AMSU-B observations. In fact, section 4.2 will show that the 150 and $183 \pm \mathrm{X} \mathrm{GHz}$ brightness temperatures are especially sensitive to the particles found at higher altitudes.

\subsection{Radiative Transfer Model:}

The radiative transfer calculations are an integral part of the retrieval method since they are used to minimize the error between the observed and the calculated brightness temperatures. The radiative transfer model requires vertical profiles of pressure, temperature and humidity as well as cloud water and cloud ice and precipitation. These quantities were obtained from the snow cloud parameterization and they were introduced into the Mie theory model. Although the scattering by snow is nearly conservative, the actual albedos for single scattering that appear in the radiative transfer model were not, because those were determined by absorption mainly due to water vapor. The albedos for single scattering thus varied with height as the constituents varied.

The radiative transfer model used to compute brightness temperatures given a hydrometeor profile is the delta-Eddington model. Microwave radiances $35^{\circ}$ off nadir were computed from a second order Eddington approximation [29] with delta scaling [30] for plane-parallel clouds. This permitted the radiances to be calculated analytically by representing them by a series of Legendre polynomials truncated after the first order. Those radiances were then inserted into the source function of the transfer equation to compute the brightness temperatures. Smith et al. [31] showed that such an algorithm produced acceptable brightness temperatures at a $53.1^{\circ}$ viewing angle, but that it yielded unacceptable errors in brightness temperatures viewed at nadir. Accordingly the phase function was approximated by representing the forward scattering component with a Dirac delta function in addition to a constant term and a term proportional to the cosine of the scattering angle. That procedure enabled both first and second moments of the approximate phase function to match those of a HenyeyGreenstein phase function. This model is identical to the previously cited Eddington second-order approximation except that the profiles of asymmetry factor, extinction coefficient and albedo for single scattering were scaled by transformed parameters. Kim et al. [32] and [31] showed that this transformation reduced the computational errors for both nadir and $53.1^{\circ}$ viewing angles. We therefore assume that the radiative transfer model is valid for AMSU-B scanning angles between those limits. 


\subsection{Snowfall Retrieval:}

The parameters $\mathbf{r}, \mathbf{f}$ and $\mathbf{m}$ were found by an optimization that sought the minimum of:

$$
\Psi(\mathbf{r}, \mathbf{f}, \mathbf{m})=\Sigma\left[\mathrm{Tb}_{\mathrm{i}}-\mathrm{Tb}_{\mathrm{i}}^{\mathrm{o}}\right]^{2}=\text { minimum }
$$

where $\mathrm{Tb}_{\mathrm{i}}$ and $\mathrm{Tb}_{\mathrm{i}}{ }^{\mathrm{O}}$ are the computed and observed brightness temperatures respectively, and the summation is over the five AMSU-B frequency channels. Since, for the current retrieval algorithm configuration, there are $11 \mathrm{r}, 6 \mathrm{f}$, and $39 \mathrm{~m}$ values, the minimization occurs over the computed brightness temperature vectors associated with these 2574 potential cloud profiles. When additional information is acquired about the snow or other aspects of the storm conditions, these can be included in Eq. (11) to further constrain the optimization. Furthermore, future versions of the retrieval algorithm will be modified for iterative optimization to allow any values of $\mathbf{r}, \mathbf{f}, \mathbf{m}$ to be selected solely by Eq. (11).

\section{Retrieval Results and Analysis:}

The retrieval was performed for the March 5-6, 2001 blizzard. The land surface temperature was assumed to be $267.5 \mathrm{~K}$ throughout the entire scene and the surface pressure was assumed to be $1010 \mathrm{mb}$. This surface temperature is a few degrees cooler than the reported inland daytime highs of $2^{\circ} \mathrm{C}$, since the local time of the AMSU-B observations was shortly after sunset. Figs. $3 \mathrm{a}, \mathrm{b}, \mathrm{c}$, and d illustrate the spatial distribution of brightness temperature errors that contributed to the $\Psi(\mathbf{r}, \mathbf{f}, \mathbf{m})$ residuals at 89,150 and $183 \pm 7,3 \mathrm{GHz}$ respectively. Because this study is confined to the determination of snowfall over land, results over water are grayed out. The theoretical and experimental brightness temperatures agreed within approximately $\pm 5 \mathrm{~K}$ over most pixels at all of the AMSU-B frequencies; including $183 \pm 1 \mathrm{GHz}$ which was not shown. The significance of the retrieved variables will be discussed in the following sections.

\subsection{Retrieved Parameters:}

Fig. 4a shows the retrieved snowfall mass density near the surface, $M_{s}(0.02 \mathrm{~km})=\mathrm{m} \mathrm{M}(0.02 \mathrm{~km})$. It is evident that the spatial distribution of the snowfall mass is qualitatively similar to the radar reflectivity displayed in Fig. 1a. Figure $4 \mathrm{~b}$ shows the distribution of the relative humidity at a $1 \mathrm{~km}$ altitude. The retrieved snow mass and relative humidity distributions are somewhat noisy. If more information were known about the profile (such as through vertical radar profiles and in-situ measurements) it is expected that these variations would be reduced. Potential sources of this noise are discussed in Section 4.3.

Figure $4 c$ shows the distribution of the parameter $f$, the fraction of snow cover on the ground within the AMSU-B field of view. Water in the Montreal, Quebec, and the St. Lawrence River regions (near $45-46 \mathrm{~N}, 73-76 \mathrm{~W}$ ) may skew the retrieved snow cover fractions because the water surfaces have a 
lower emissivity than dry ground surfaces assumed in Eq. (2). The retrieval algorithm erroneously compensates for these lower emissivities (that produce cooler $\mathrm{Tb}$ ) by increasing the snow fraction.

\subsection{Weighting Functions:}

Temperature weighting vector profiles [33] can be used to understand contributions to brightness temperatures from each layer of the atmosphere, the cosmic background, and the ground. The brightness temperature at each frequency is the integrated sum over all heights of the product of the weighting vector value and the atmospheric temperature plus the contributions from the ground and cosmic background temperatures:

$$
T b=\int_{0}^{\infty} T(z) W(z) d z=T_{0} W_{0}+T_{C B} W_{C B}+\sum_{i=1}^{l} T(i) W_{A L L}(i) \Delta z_{i}
$$

where the subscripts 0 (at $z=0$ ), and $C B$ denote ground surface and cosmic background, $T(i), W_{A L L}(i)$ denote the temperature and weighting vector value for level $i$ of the cloud profile that consists of I levels, and $\Delta z$ is the height increment between level $i$ and level $i-1$. The weighting vectors depend on the profiles of the atmospheric cloud constituents and will change for various representative profiles. The weighting vectors $W_{A L L}, W_{S}$, and $W_{C B}$ are defined in [33] where $W_{A L L}$ is denoted $W^{(n)}$. The $W_{A L L}$ includes the effects of multiple scattering by snow (S), and absorption by snow, water vapor (WV), nitrogen $\left(\mathrm{N}_{2}\right)$, and oxygen $\left(\mathrm{O}_{2}\right)$.

In order to determine the contributions to the brightness temperature value from snow, water vapor, and other constituents, $W_{A L L} T(z)$ (with units of $\mathrm{K} \mathrm{km}^{-1}$ ) at each height is revised:

$$
W_{A L L}(z) T(z)=M_{S}(z) W_{S N O W}(z)+R H(z) W_{W V}(z)+W_{o t h e r}(z) T(z)
$$

We then define $W_{S}, W_{W V}$, and $W_{\text {other }}$ as:

$$
\begin{array}{rc}
W_{S}(z)=\frac{k_{\text {Sext }}(z) T(z) W_{A L L}(z)}{k_{e x t}(z) M_{S}(z)} & \left(\mathrm{K} \mathrm{km}^{-1} \mathrm{~m}^{3} \mathrm{~g}^{-1}\right) \\
W_{W V}(z)=\frac{k_{W V}(z) T(z) W_{A L L}(z)}{k_{e x t}(z) R H(z)} & \left(\mathrm{K} \mathrm{km}^{-1} \%{ }^{-1}\right) \\
W_{\text {other }}(z)=\frac{\left[k_{O 2}(z)+k_{N 2}(z)\right] W_{A L L}(z)}{k_{e x t}(z)} & \left(\mathrm{km}^{-1}\right)
\end{array}
$$

where

$$
k_{e x t}=k_{S, e x t}+k_{W V}+k_{O 2}+k_{N 2}
$$

The $k_{S, \text { ext }}$ term is the sum of the absorption and scattering coefficients for snow found in Eq. $9, k_{W V}$ is the absorption coefficient for water vapor, and $k_{O 2}$ and $k_{N 2}$ are the absorption coefficients for $\mathrm{O}_{2}$, and 
$\mathrm{N}_{2}$. Note that $k_{\text {ext }}$ is also used in integrals within $W_{A L L}$ as the atmospheric opacity. This means that $W_{S}$ is not entirely free of the effects of the water vapor and other constituents, and likewise for $W_{W V}$ and $W_{\text {other }}$ however, they do respond to most of the information about the snow, water vapor, and other constituents, respectively.

In order to illustrate the physics of this retrieval, two representative retrieved profiles are studied. The first retrieved profile is extracted near the heaviest snowfall region, at $42.52 \mathrm{~N}, 72.036 \mathrm{~W}$. The second profile at $40.77 \mathrm{~N}, 72.36 \mathrm{~W}$ is a lighter snowfall case and it is also much drier. For the first profile, Eq. (11) selects $\mathbf{r}=0.7, \mathbf{m}=2.6 \mathrm{~g} \mathrm{~m}^{-3}$, and $\mathbf{f}=0.8$ and for the second profile $\mathbf{r}=0.3, \mathbf{m}=0.6 \mathrm{~g} \mathrm{~m}^{-3}$, and $\mathbf{f}$ $=0.4$. The retrieved snow and relative humidity profiles and surface emissivity can be computed using Eqns. (1), (2), (3) and the profile information in Table 1.

Table II compares, the observed and computed brightness temperatures for these two representative retrieved profiles. This table shows fairly good agreement for all but the profile $2183 \pm 1 \mathrm{GHz}$ channel where there is a $5 \mathrm{~K}$ difference. This disagreement is likely due to a mismatch in the relative humidity for the second profile.

Table II. Brightness temperature values (in $K$ ) for two representative profiles.

\begin{tabular}{|c|c|c|c|c|}
\hline & Profile 1 & Profile 1 & Profile 2 & Profile 2 \\
\hline & AMSU-B & Retrieved & AMSU-B & Retrieved \\
\hline $89 \mathrm{GHz}$ & 209.2 & 206.5 & 233.9 & 232.0 \\
\hline $150 \mathrm{GHz}$ & 185.5 & 185.7 & 221.4 & 219.5 \\
\hline $183 \pm 1 \mathrm{GHz}$ & 236.8 & 237.2 & 241.4 & 246.3 \\
\hline $183 \pm 3 \mathrm{GHz}$ & 234.1 & 232.9 & 244.3 & 247.4 \\
\hline $183 \pm 7 \mathrm{GHz}$ & 210.1 & 209.4 & 235.1 & 236.0 \\
\hline
\end{tabular}

Plots of $W_{A L L}(z) T(z), W_{S}(z) M_{s}(z)$, and $W_{W V}(z) R H(z)$ are shown in Figure 5 for the two representative profiles. These plots can be used to determine the brightness temperature (by integrating over the heights and adding the cosmic background and surface contributions provided in Table 3). The $W_{w V}(z) R H(z)$ plots (Fig. $5 \mathrm{c}$ and $\mathrm{f}$ ) show that the contribution of water vapor to the $183.3 \pm 1$ and \pm 3 $\mathrm{GHz}$ brightness temperature is high at higher altitudes (above $5 \mathrm{~km}$ ). For the other frequencies, the water vapor contribution is inversely correlated with the amount of snow in the cloud. By examining Fig $5 \mathrm{~b}$ and $\mathrm{d}$, it is noted that a decrease in $\mathrm{m}$ from 2.6 (Fig. $5 \mathrm{~b}$ ) to $0.6 \mathrm{~g} \mathrm{~m}^{-3}$ (Fig. $5 \mathrm{~d}$ ) reduces the contribution from snow by about one half. Furthermore it should be noted that the $183 \mathrm{GHz}$ channels response to snow above the Earth's surface, while the 89 and $150 \mathrm{GHz}$ respond more intensely near the surface. The 89 and $150 \mathrm{GHz}$ channels are also more sensitive to the surface emissivity, so some tradeoff must be made between the surface contributions and the snow contributions and contamination of the signal may occur. The $150 \mathrm{GHz}$ channel is a little more immune to surface effects if the snow mass profile is large enough. 
Table III. Surface and cosmic background weights and brightness temperature contributions for three retrieved profiles.

\begin{tabular}{|c|c|c|c|c|}
\hline & Profile 1 & Profile 1 & Profile 2 & Profile 2 \\
\hline & $T_{0} W_{0}$ & $T_{C B} W_{C B}$ & $T_{0} W_{0}$ & $T_{C B} W_{C B}$ \\
\hline $89 \mathrm{GHz}$ & 111.8 & 0.5 & 180.8 & 0.37 \\
\hline $150 \mathrm{GHz}$ & 25.7 & 0.8 & 110.9 & 0.5 \\
\hline $183 \pm 1 \mathrm{GHz}$ & $\sim 0.0$ & 0.1 & 0.01 & 0.06 \\
\hline $183 \pm 3 \mathrm{GHz}$ & 0.02 & 0.29 & 0.65 & 0.15 \\
\hline $183 \pm 7 \mathrm{GHz}$ & 1.4 & 0.55 & 16.4 & 0.33 \\
\hline
\end{tabular}

The $T_{0} W_{0}$ in Table III show that the surface contribution from the $89 \mathrm{GHz}$ channel is larger than that of the other channels and increases as we move from profile 1 to profile 2 . In fact, the surface contributes at least half of the value of the resulting brightness temperatures for $89 \mathrm{GHz}$. A similar effect is seen for the $150 \mathrm{GHz}$ surface weighting values, though heavy snow will obscure the surface for $150 \mathrm{GHz}$ (Profile 1). The $183 \pm \mathrm{X} \mathrm{GHz}$ channels receive very little of their resultant brightness temperature values from the surface. All of the cosmic background contributions, $T_{C B} W_{C B}$, are small.

\subsection{Radar Reflectivity vs. Melted Snowfall Rain Rate}

A pixel area matching technique similar to that described by [34] was used to relate the radar reflectivity, $Z_{\text {eff }}\left(\mathrm{mm}^{6} \mathrm{~m}^{-3}\right)$, derived from the $\mathrm{dBZ}_{\text {eff }}$ over land shown in Fig. 1a to the retrieved snowfall mass distribution, $M_{s}(0.02 \mathrm{~km})$ retrieved from the microwave data shown in Fig. $4 \mathrm{a}$. The - procedure selected a number of pixels that exceeded a given snowfall mass and the same number of pixels that exceeded a particular radar reflectivity. Threshold values of each of these quantities were tabulated. The terminal velocity of snowflakes was assumed to be $\sim 1 \mathrm{~m} \mathrm{~s}^{-1}$ so that the melted snowfall rates, $R\left(\mathrm{~mm} \mathrm{~h}^{-1}\right)$, could be derived by multiplying $M_{s}(0.02 \mathrm{~km})$ by that terminal velocity.

Fig. 6 presents $\mathrm{dB} Z_{\text {eff }}$ as a function of $\log (R)$ derived from this pixel matching technique for the retrieval results reported in Fig. 4. These results are compared to some representative $Z_{\text {eff }}-R$ relationships [35]-[38] that showed that the coefficients of snow $Z_{\text {eff }}-R$ relationships could vary over a wide range. The coefficients in such $Z_{\text {eff }}-R$ relationships have been refined over the years as snow measuring techniques have become more sophisticated. The comparison of the retrieved relationship to some previously published relationships is surprisingly good. While this is not a direct validation of the retrieval results, it does show that this physical model enables retrievals to fall within existing measured and empirical relationship bounds.

\subsection{Error Discussion:}

Because there are only 3-4 degrees of freedom associated with the AMSU-B channels and few additional measurements to further constrain the retrievals, the number of parameters retrieved is limited. With a limited retrieved parameter set, assumptions were made about the vertical structure of the snow cloud, including fixed vertical profiles of temperature, water vapor, and snow mass shape. Unfortunately, these assumed profiles, taken from the MM5 cloud model simulations, could not be validated by in situ observations. Further constraints were made on the allowed variability of the snow 
particle characteristics, by keeping the snow particle effective diameter relatively fixed throughout the profiles (but allowing the snow mass index, $\mathbf{m}$ to vary).

Determining the electromagnetic (scattering, absorption, and asymmetry) properties of the snow leads to additional assumptions. The ones used herein include assuming dry snow, that the Grenfell and Warren [21] approach to redistributing low-density fluffy snow into small ice spheres is appropriate and that the snow attenuation measured by [25] and [26] applied to the present case with a minor modification of the particle size. Fig. 2 showed that the attenuation of the particles assuming the G-W approach is relatively consistent with independently measured attenuation of snowfall. Other research $[3,39]$ on anvil ice particles and snowfall has shown that the retrieved particles sizes can be smaller than expected giving credence to the applicability of the Grenfell and Warren approach. A detailed future analysis should include in situ sampling of snow particles that simultaneously determines size distributions and electromagnetic characteristics.

The noise in the retrieved snow mass, relative humidity indices and surface emissivity may be attributed to some of the assumptions made in this physically-based retrieval:

1. Selection of a single shape, $M(z)$, for the snow mass profiles. Eq (3).

2. Selecting a step function to describe the snow size distribution with height, Eq. (10).

3. Assuming that equivalent spheres suffice to describe the electromagnetic properties of these frozen hydrometeors. Eq. (4-7).

4. Assuming that the snow measured by [25], [26] had the same habit as that at the surface in this New England blizzard.

5. Ignoring frozen hydrometeors other than snow and assuming that snow was dry.

6. Allowing the relative humidity index to vary independently of the snow mass index.

7. Assuming that topography had no influence on the surface emissivity other than that represented by Eq. (2).

Another source of error and uncertainty is the conversion of the NOAA NWS composite data into reflectivities associated with snow falling near the ground. Radar validation of the melted snowfall rates retrieved from microwave brightness temperatures are fraught with large uncertainties both in terms of calibration of the operational NWS radars and the choice of the appropriate height from which measurements were blended to produce the mosaic of reflectivity values. While, the reflectivities presented in summaries of operational NWS radars were not calibrated for research; they provide information about the intensity and horizontal structure of the storm. In the absence of a dedicated measurement campaign the snowfall melted rain rates yielded a $Z_{\text {eff }}-R$ relationship that was consistent with previous measurements.

\section{Discussion and Conclusions:}

A physically based retrieval algorithm was developed to estimate snowfall over land. The retrieval algorithm relied on a multi-parameter cloud model to generate the vertical structure of a snow cloud, including snow mass, snow particle effective diameter, and water vapor. The MM5 cloud simulation was used to provide useful statistics for generating those cloud characteristics. Ground-based attenuation measurements were used to characterize the equivalent sphere snow particle size used 
herein. The snow cloud profile and surface emissivity were then used in radiative transfer calculations that were optimized against AMSU-B observations at 89,150 and $183.3 \pm 7, \pm 3$, and $\pm 1 \mathrm{GHz}$. For each pixel in the image, the multi-parameter cloud parameterization that produced brightness temperatures that best fit the AMSU-B observations was selected as the retrieved profile. The present study demonstrated:

1. Microwave radiometric channels operating at frequencies greater than $89 \mathrm{GHz}$ provide information on snowfall over variable land surfaces because the surface emissivity is screened by water vapor absorption at those frequencies.

2. An electromagnetic scattering model of randomly oriented snow particles was adequately represented as equivalent spheres whose diameters were mainly determined by the small dimensions of the snow particles as suggested by the work of Grenfell and Warren [21]. That model accounted for measured values of attenuation per unit mass between 96 and $225 \mathrm{GHz}$. Inserting the G-W "equivalent" ice spheres in a delta-Eddington radiative transfer model yielded brightness temperatures at 89,150 and $183 \pm 1, \pm 3, \pm 7 \mathrm{GHz}$ that were consistent with values measured by AMSU within $\pm \sim 5 \mathrm{~K}$. This was in part due to the fact that the diameters of the equivalent particles were small so that the asymmetry factor was also small (as might be expected from Rayleigh-like scattering). Small asymmetry factors reduce the transmission of snow layers, thereby achieving lower brightness temperatures than those produced by a low-density fluffy snow particle ice-air effective medium with larger asymmetry factors.

3. Weighting vectors illustrated the relationships between the physical properties of the clouds (snow and water vapor characteristics) and the resulting brightness temperatures.

4. Three variables used to adjust the snow mass, relative humidity and surface emissivity were sufficient to estimate snowfall rates consistent with NWS radar reflectivity measurements and to yield a $Z_{\text {eff }}-R$ relationship that was consistent with others reported in the literature.

The number of retrieved parameters was kept to a minimum because there are only 3-4 degrees of freedom in the five AMSU-B channels. This study emphasizes the need for a dedicated set of coincident observations that include microwave as well as microphysics measurements. Field campaigns are needed to measure the high frequency electromagnetic properties of snow along with the habits of frozen hydrometeors to yield parameters that we were forced to derive from disparate observations. Such measurements need to include the small as well as the large dimensions of frozen hydrometeors. More realistic retrieval procedures can be developed when additional information becomes available.

\section{Acknowledgments:}

We wish to thank Drs. Ralph Ferraro and Huan Meng of NOAA for providing NOAA-15 AMSU data, Professor Robert Houze of the University of Washington for insights regarding cloud physics, Dr. David Kitzmiller of the National Weather Service for describing the procedures used to produce the NWS radar reflectivity composites. We thank Allen Lunsford of GST in the NASA Goddard Code 935 for converting the NWS radar images into a quantitative data record. We are also grateful to Drs. Tom 
Grenfell and Professor Steve Warren for valuable discussions regarding their work on IR scattering characteristics of ice particles. Interest in our work by Dr. Ramesh Kakar of Code Y at NASA HQ and support from the Goddard Director's Discretionary Fund are also gratefully acknowledged.

\section{References:}

[1] R.A. Houze, Jr. Cloud Dynamics, San Diego, CA: Academic Press Inc., 1993.

[2] A. Chang and T. Koike, "Progress in AMSR snow algorithm development," in Microw. Radiomet. Remote Sens. Earth's Surf. Atmosphere, P. Pampaloni, S. Paloscia Eds. 2000, pp. 515-523.

[3] J.A. Weinman and I.M. Hakkarinen, "Determination of maritime snowfall from radar and microwave radiometer measurements," in AMS Conf. on Cloud Physics, San Francisco, CA, 1990.

[4] G. Liu and J.A. Curry, "Large-scale cloud features during January 1993 in the North Atlantic Ocean as determined from SSM/I and SSM/T2 observations," J. Geophys. Res., vol. 101, pp. 7019$7031,1996$.

[5] J.L. Schols, J.A. Weinman, G.D. Alexander, R.E. Stewart, L.F. Angus and A.C. Lee, "Microwave properties of frozen precipitation around a North Atlantic cyclone," J. Appl. Met., vol. 38, pp. 29-43, 1999.

[6] R. Bennartz and G.W. Petty, "The sensitivity of microwave remote sensing observations of precipitation to ice particle size distributions," J. Appl. Met., vol. 40, pp. 345-364, 2001.

[7] C. Kongoli, P. Pellegrino, R. Ferraro, and N. Grody, "Identification and retrieval of snowfall over land from the Advanced Microwave Sounding Unit (AMSU)," presented at the $83^{\text {rd }}$ Annual Meeting, Am. Met. Soc., Long Beach, CA, 2003.

[8] F. W. Chen, and D. H. Staelin, "AIRS/AMSU/HSB precipitation estimates," IEEE Trans. Geosci. Remote Sens., vol. 41, pp. 410-417, 2003.

[9] R.W. Saunders, T.J. Hewison, N.C. Atkinson, and S.J. Stringer, "The radiometric characterization of AMSU-B," IEEE Trans. Microwave Theory Tech., vol. 43, pp. 760-771, 1995.

[10] J. Dudhia, "A nonhydrostatic version of the Penn State-NCAR mesoscale model: Validation tests and simulation of an Atlantic cyclone and cold front," Mon. Wea. Rev., vol. 121, pp. 1493-1513,1993.

[11] G.A. Grell, J. Dudhia, and D. R. Stauffer, "A description of the fifth-generation Penn State/NCAR Mesoscale Model (MM5)," NCAR Tech. Note NCAR/TN-398 + STR, 1995.

[12] D.E. Chang, J.A. Weinman, C.A. Morales, and W.S. Olson, "The effect of spaceborne microwave and ground-based continuous lightning measurements on forecasts of the 1998 groundhog day storm," Mon. Wea. Rev., vol. 129, pp. 1809-1833, 2001. 
[13] R. E. Orville, and G. R. Huffines, "Cloud-to-ground lightning in the United States: NLDN results in the first decade 1989-98," Monthly Weather Review, vol. 129, pp. 1179-1193, 2001.

[14] T. J. Hewison and S.J. English, "Airborne retrievals of snow and ice surface emissivity at millimeter wavelengths," IEEE Trans. Geosci. Remote Sens., vol. 37, pp. 1871-1879, 1999.

[15] T. J. Hewison, "Airborne measurements of forest and agricultural and surface emissivity at millimeter wavelengths," IEEE Trans. Geosci. Remote Sens., vol. 39, pp. 393-400, 2001.

[16] S.A. Rutledge and P.V. Hobbs "The mesoscale and microscale structure of and organization of clouds and precipitation in mid-latitude clouds Part XII A diagnostic modeling study of precipitation in narrow cold frontal rainbands," J. Atm. Sci., vol. 41, pp. 2949-2972, 1984.

[17] C.F. Bohren and L.J. Battan, "Radar backscattering of microwaves by spongy ice particles," $J$. Atm Sci., vol. 39, pp. 2623-2628, 1982.

[18] R. Meneghini and L. Liao, "Effective dielectric constants of mixed-phase hydrometeors," $J$. Atmos. Oceanic Technol., vol. 17, no. 5, pp. 628-640, 2000.

[19] A. H. Sihvola, "Self-consistency aspects of dielectric mixing theories," IEEE Trans. on Geosci. and Remote Sens., vol. 27, pp. 403-415, 1989.

[20] C. Tang and K. Aydin, "Scattering from ice crystals at 94 and $220 \mathrm{GHz}$ millimeter wave frequencies," IEEE Trans. on Geosci. and Remote Sens., vol. 35, pp. 93-99, 1995.

[21] T. C. Grenfell and S.G. Warren, "Representation of a nonspherical ice particle by a collection of independent spheres for scattering and absorption of radiation," J. Geophys. Res., vol. 104, pp. 31,697$31,709,1999$.

[22] J.S. Foot, "Some observations of the optical properties of clouds, Part II, Cirrus," Quart. J. Roy. Meteor. Soc., vol. 114, pp. 145-164, 1988.

[23] Q. Fu, "An accurate parametrization of the solar radiative properties of cirrus clouds for climate models," J. Cli., vol. 9, pp. 2058-2082, 1996.

[24] S.P. Neshyba, T.C. Grenfell, and S.G. Warren, "Representation of a hexagonal ice crystal by a collection of independent spheres for scattering and absorption of radiation," Presented at $11^{\text {th }}$ Conf. on Atmospheric Radiation, Ogden, UT, June 3-7, 2002, Paper JP3.

[25] J. Nemarich, R.J. Wellman, and J. Lacombe, "Backscatter and attenuation by falling snow and rain at 96, 140 and 225 GHz," IEEE Trans. on Geosci. and Remote Sens., vol. 26, pp. 319-329, 1988.

[26] H. B. Wallace, "Millimeter-wave propagation measurements at the Ballistic Research Laboratory," IEEE Trans. on Geosci. and Remote Sensing, vol. 26, pp. 253-258, 1988. 
[27] A.H. Auer Jr, and D.L. Veal, "The dimensions of ice crystals in natural clouds," J. Atm. Sci., vol. 27, pp. 919-926, 1970.

[27] P.V. Hobbs, S. Chang, and J.D. Locatelli, "The dimensions and aggregation of ice crystals in natural clouds," J. Geophys. Res., vol. 79, pp. 2199-2206, 1974.

[29] J.A. Weinman and R. Davies, "Thermal microwave radiances from horizontally finite clouds of hydrometeors," J. Geophys. Res., vol. 83, pp. 3099-3107, 1978.

[30] G.E. Thomas and J. Stamnes, Radiative Transfer in the Atmosphere and Ocean, Cambridge, United Kingdom, Cambridge University Press, 1999.

[31] E.A. Smith, P.Bauer, F.S. Marzano, C.D. Kummerow, D. McKague, A. Mugnai, and G.Panegrossi, "Intercomparison of microwave radiative transfer models for precipitating clouds," IEEE Trans. on Geosci. and Remote Sensing, vol. 40, pp. 541-549, 2002.

[32] M.J. Kim, G. Skofronick-Jackson, and J.A. Weinman, "Intercomparison of millimeter-wave radiative transfer models," in Proceedings of International Geoscience and Remote Sens Symposium, Toulouse, France, July 21-25, 2003.

[33] A.J. Gasiewski, "Microwave Radiative Transfer in Hydrometeors," in Atmospheric Remote Sensing by Microwave Radiometry, M. A. Janssen, Ed., New York, NY: John Wiley and Sons, 1993, pp. 91-144.

[34] R.V. Calheiros and I. Zawadski, "Reflectivity-rain rate relationship for radar hydrology in Brazil," J. Cli. and Appl. Met., vol. 26, pp. 118-132, 1987.

[35] Y. Fujiyoshi, T. Endoh, T. Yamada, K. Tsuboki, Y. Tachibana, and G. Wakahama, "Determination of a Z-R relationship for snowfall using a radar and high sensitivity snow gauges," $J$. Appl. Met., vol. 29, pp. 147-152, 1990.

[36] S. Vasiloff, R.M. Rasmussen, M. Dixon, and F. Hage, "Evaluation of snow forecasts provided by the Weather Support DeIcing Decision Making (WSDDM) system," in Ninth Conf. On Aviation, Range and Aerospace Meteorology, Orlando FL, 2000, pp. 547-550.

[37] R.S. Sekhon and R.C. Srivastava, "Snow size spectra and radar reflectivity," J. Atm. Sci., vol. 28, pp. 983-944, 1970.

[38] R.J. Boucher and J.G. Weiler, "Radar determination of snowfall rate and accumulation," J. Cli. and Appl. Meteor., vol. 24, pp. 68-73, 1985.

[39] G.M. Skofronick-Jackson, J.R. Wang, G.M. Heymsfield, R. Hood, W. Manning, R. Meneghini, and J.A. Weinman, "Combined radiometer-radar microphysical profile estimations with emphasis on high-frequency brightness temperature observations," J. Appl. Met., vol. 42, no. 4, pp. 476-487, 2003. 


\section{Table Captions:}

Table I. Atmospheric parameters inferred from MM5 model of the 5-6 March 2001 blizzard.

Table II. Brightness temperature values for three retrieved profiles.

Table III. Surface and cosmic background weights and brightness temperature contributions for three retrieved profiles.

\section{Figure Captions:}

Fig. 1 (a) Radar reflectivity (dBZ) obtained from the NWS operational radar composite measured at 23:00 UTC 5 March 2001 and AMSU-B brightness temperatures observed 23:02 UTC 5 March 2001 (b) $150 \mathrm{GHz}$, (c) $89 \mathrm{GHz}$, (d) $183+7 \mathrm{GHz}$ (e) $183+3 \mathrm{GHz}$, and (f) $183+1 \mathrm{GHz}$.

Fig. 2 Comparison between the attenuation per unit mass density $\left(\mathrm{dB} / \mathrm{km} / \mathrm{gm} / \mathrm{m}^{3}\right)$ of snow versus frequency. Calculations (solid lines) are compared to various measurements by (o) Wallace, 1988 (1981 measurements), (X) Wallace, 1988 (1982 measurements) and (ㅁ) Nemarich et al, 1988.

Figs. 3 a), b), c), and d) Differences between optimized computed brightness temperatures and measured brightness temperatures at $89,150,183 \pm 7$, and $183 \pm 3 \mathrm{GHz}$ respectively.

Figure 4 The distribution of retrieved (a) snow mass at $20 \mathrm{~m}$ above the surface, (b) relative humidity at $1 \mathrm{~km}$ height, and (c) fractional snow cover.

Figure 5: The total, snow, and relative humidity weighting vectors of two sampled retrieved profiles, $(a, b, c)$ near the most intense snowfall region, and $(d, e, f)$ near the storm boundary with low relative humidity.

Figure 6 Measured NWS radar reflectivity, $\mathrm{Z}$, versus melted snowfall rate, $\mathrm{R},\left(\mathrm{mm} \mathrm{h}^{-1}\right)$ inferred from the $\mathrm{M}_{\mathrm{s}}(0)\left(-\mathrm{X}^{-} \mathrm{X}^{-}\right)$. Results are compared to Z-R relationships found by Sekhon and Srivastava ( - - ), Vasiloff et al. ( - - - ) and by Fujiyoshi et al. ( - ), and Boucher and Weiler (……). 

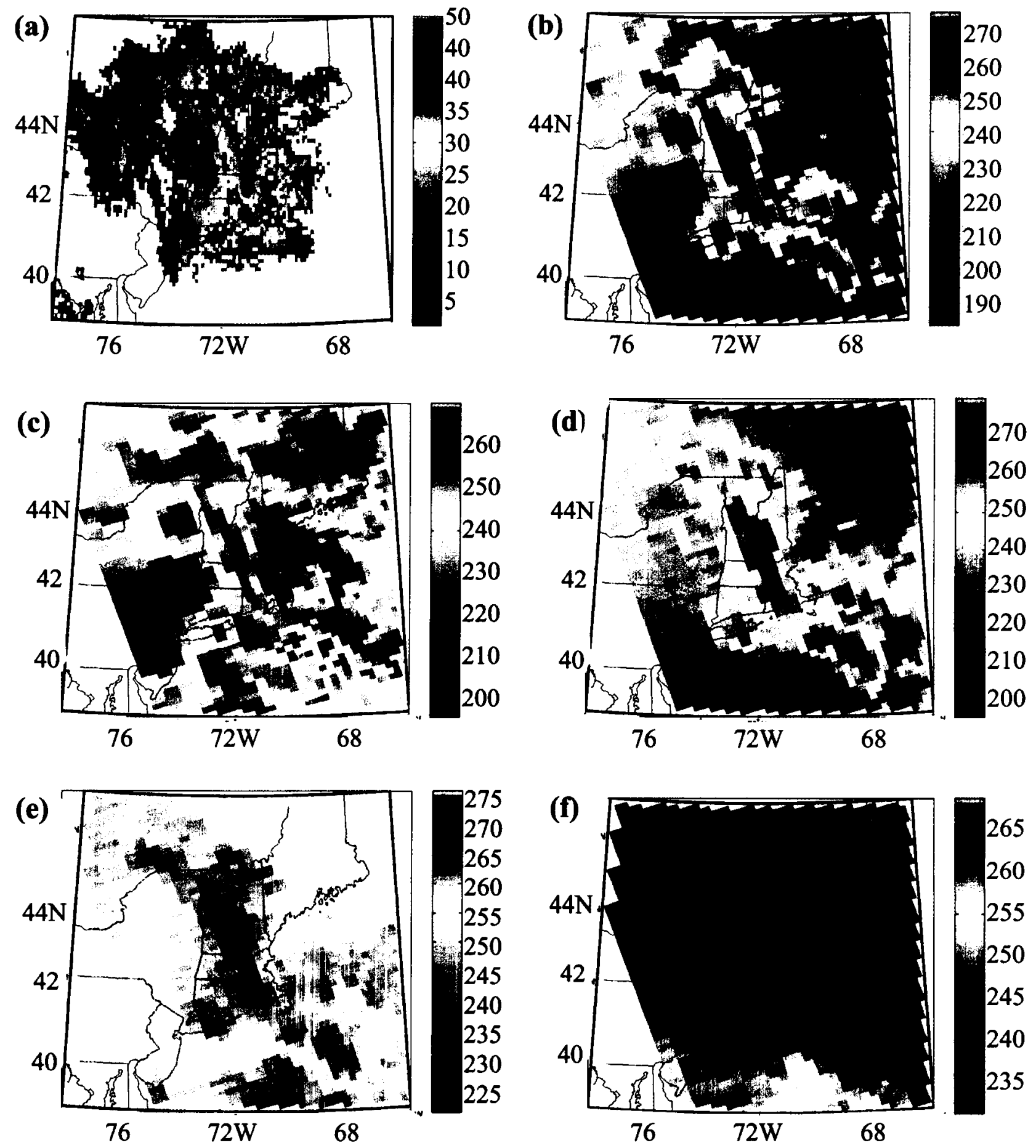

Fig. 1 (a) Radar reflectivity (dBZ) obtained from the NWS operational radar composite measured at 23:00 UTC 5 March 2001 and AMSU-B brightness temperatures observed 23:02 UTC 5 March 2001 (b) $150 \mathrm{GHz}$, (c) $89 \mathrm{GHz}$, (d) $183 \pm 7 \mathrm{GHz}$ (e) $183 \pm 3 \mathrm{GHz}$, and (f) $183 \pm 1 \mathrm{GHz}$. 


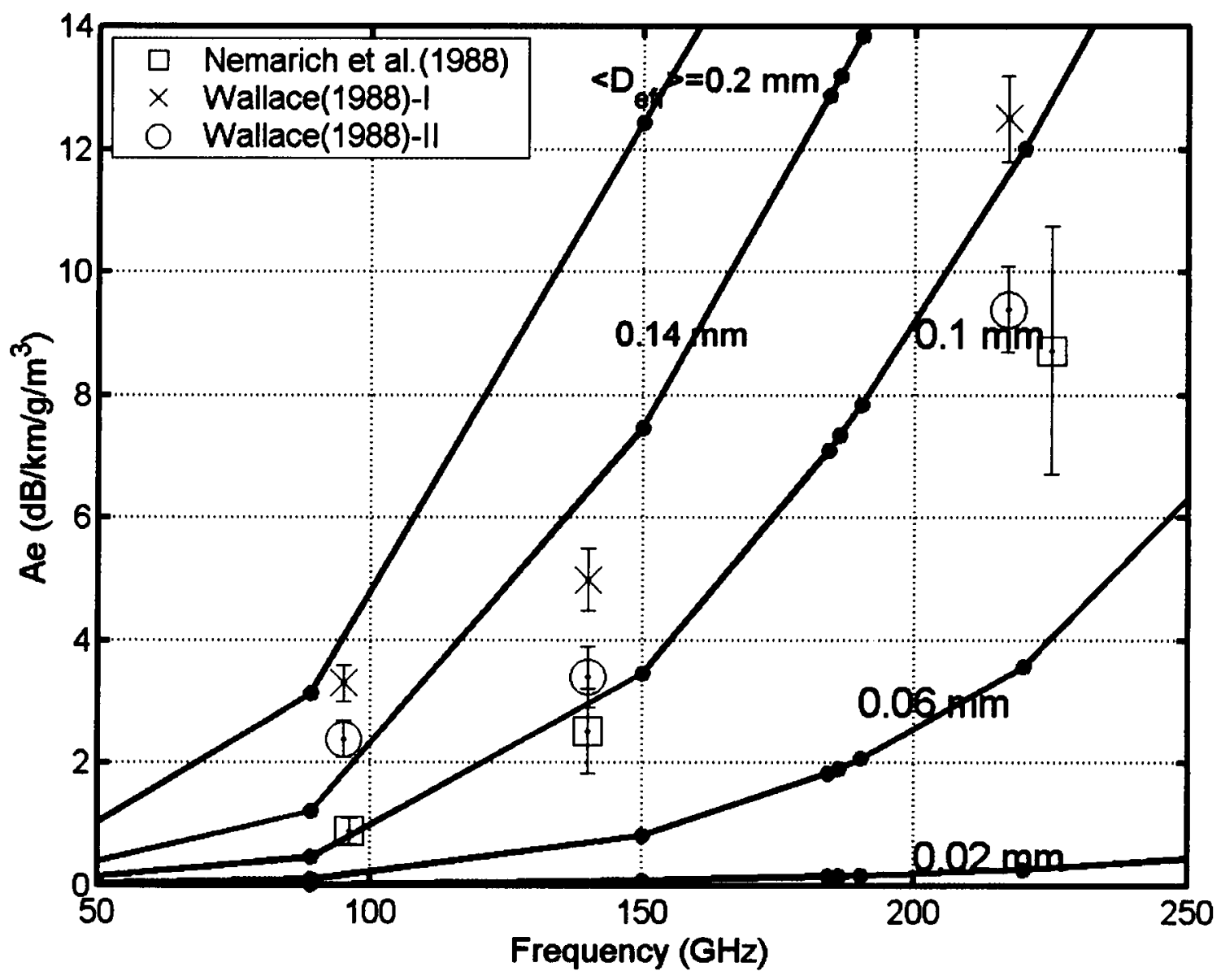

Fig. 2 Comparison between the attenuation per unit mass density $\left(\mathrm{dB} / \mathrm{km} / \mathrm{gm} / \mathrm{m}^{3}\right)$ of snow versus frequency. Calculations (solid lines) are compared to various measurements by (o) Wallace, 1988 (1981 measurements), (X) Wallace, 1988 (1982 measurements) and () Nemarich et al, 1988. 

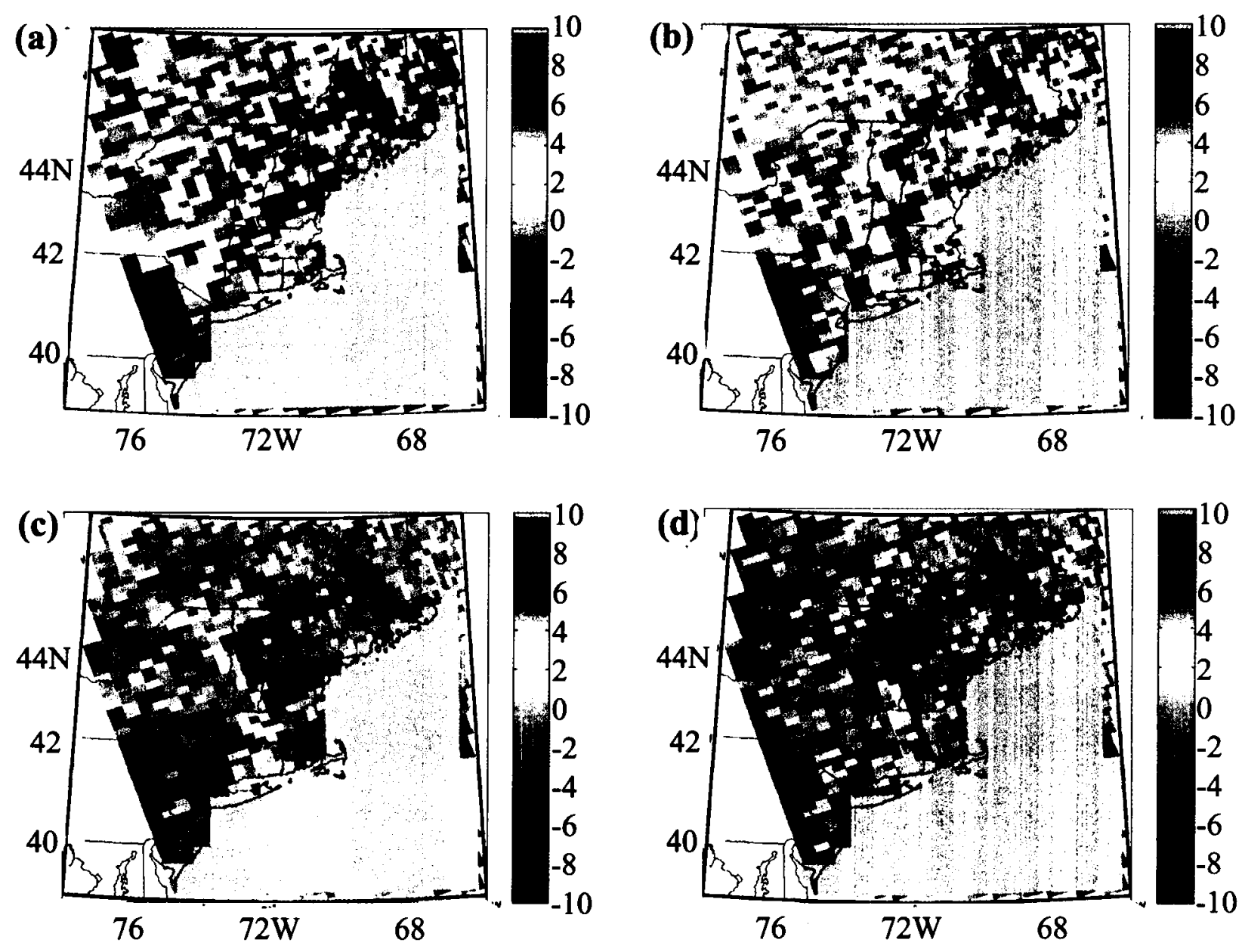

Figs. 3 a), b), c), and d) Differences between optimized computed brightness temperatures and measured brightness temperatures at $89,150,183 \pm 7$, and $183 \pm 3 \mathrm{GHz}$, respectively. 

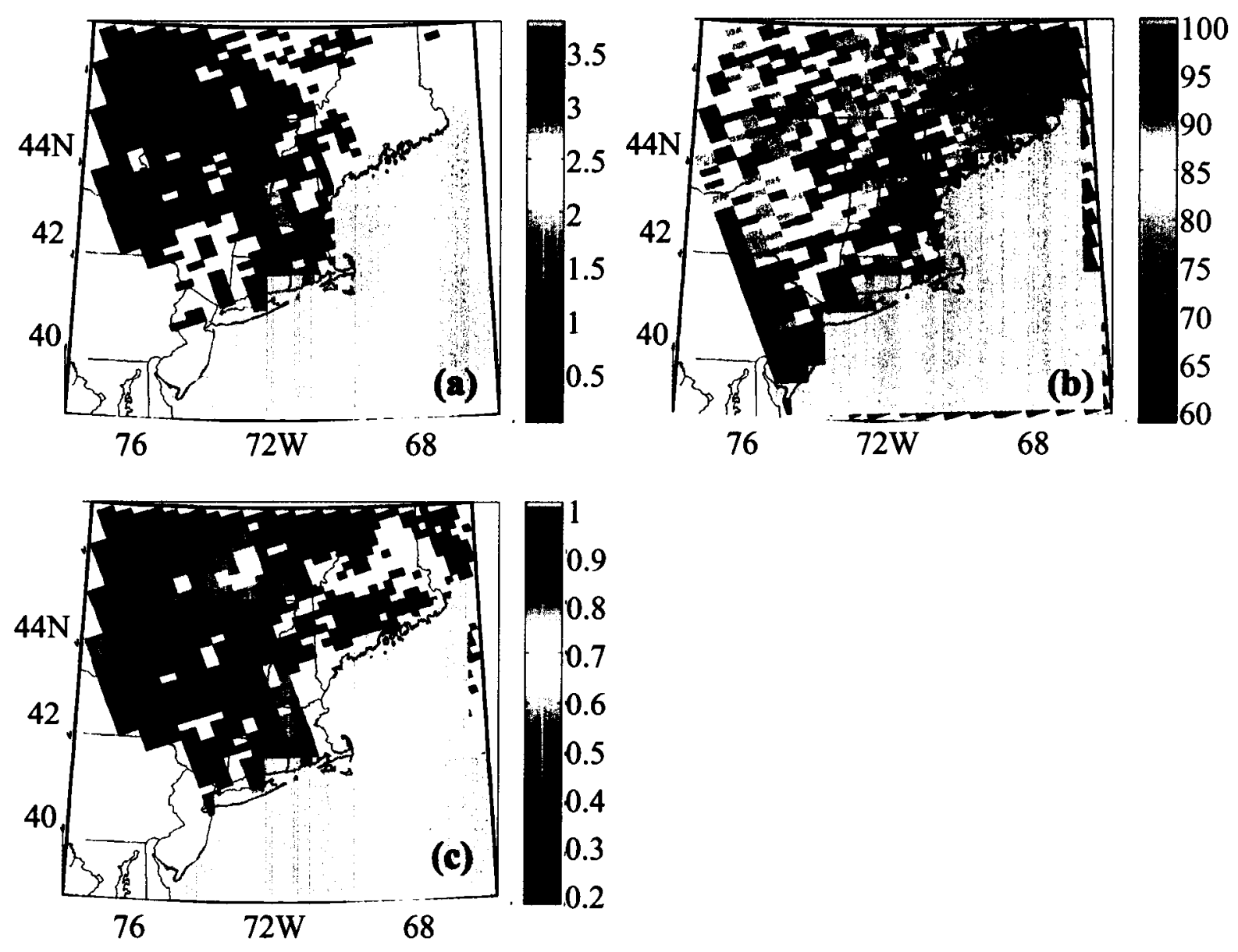

Fig. 4 The distribution of retrieved (a) snow mass at $20 \mathrm{~m}$ above the surface, (b) relative humidity at 1 $\mathrm{km}$ height, and (c) fractional snow cover. 

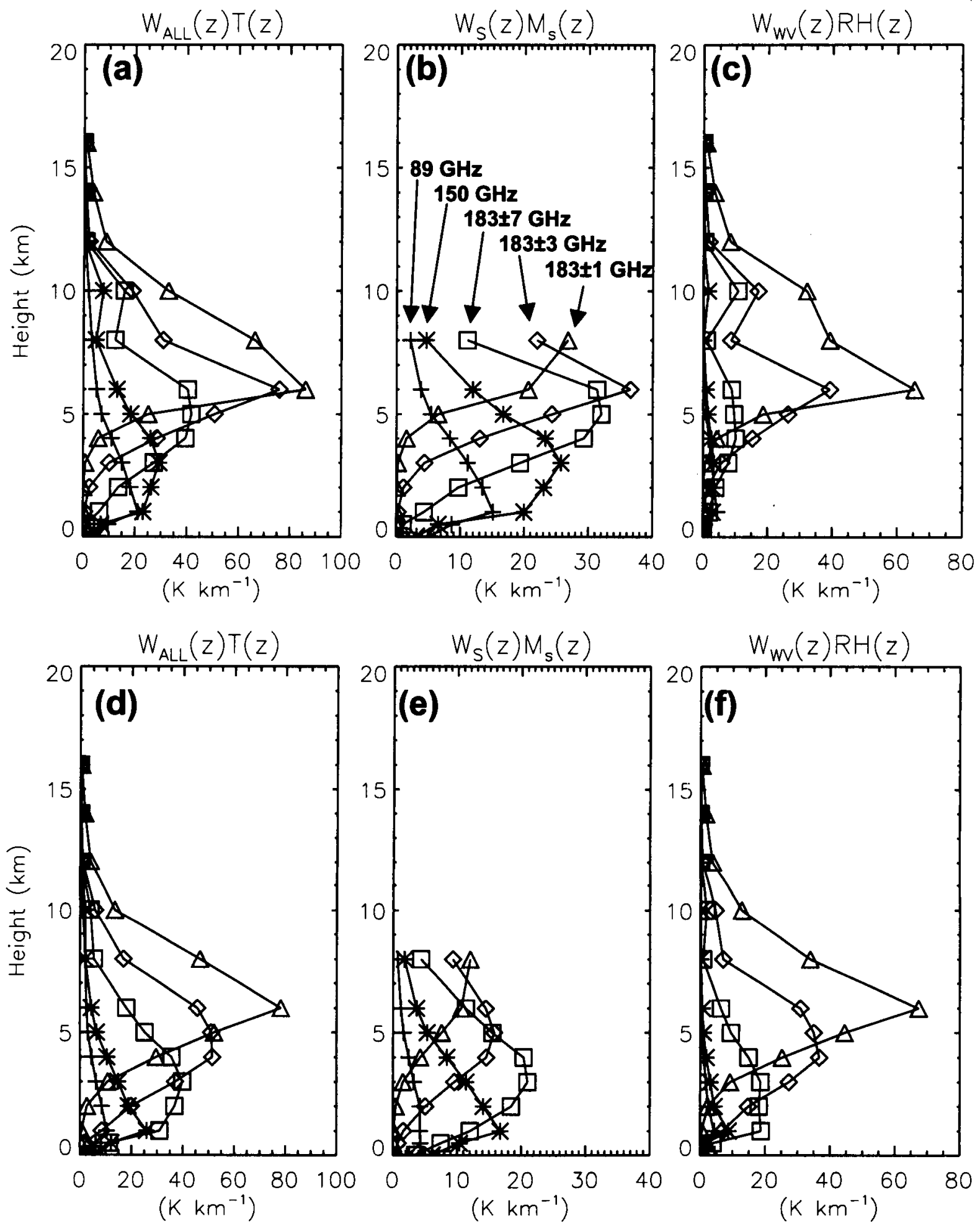

Fig. 5 The total, snow, and relative humidity weighting vectors of two sampled retrieved profiles, (a, $b, c)$ near the most intense snowfall region, and $(\mathrm{d}, \mathrm{e}, \mathrm{f})$ near the storm boundary with low relative humidity. 


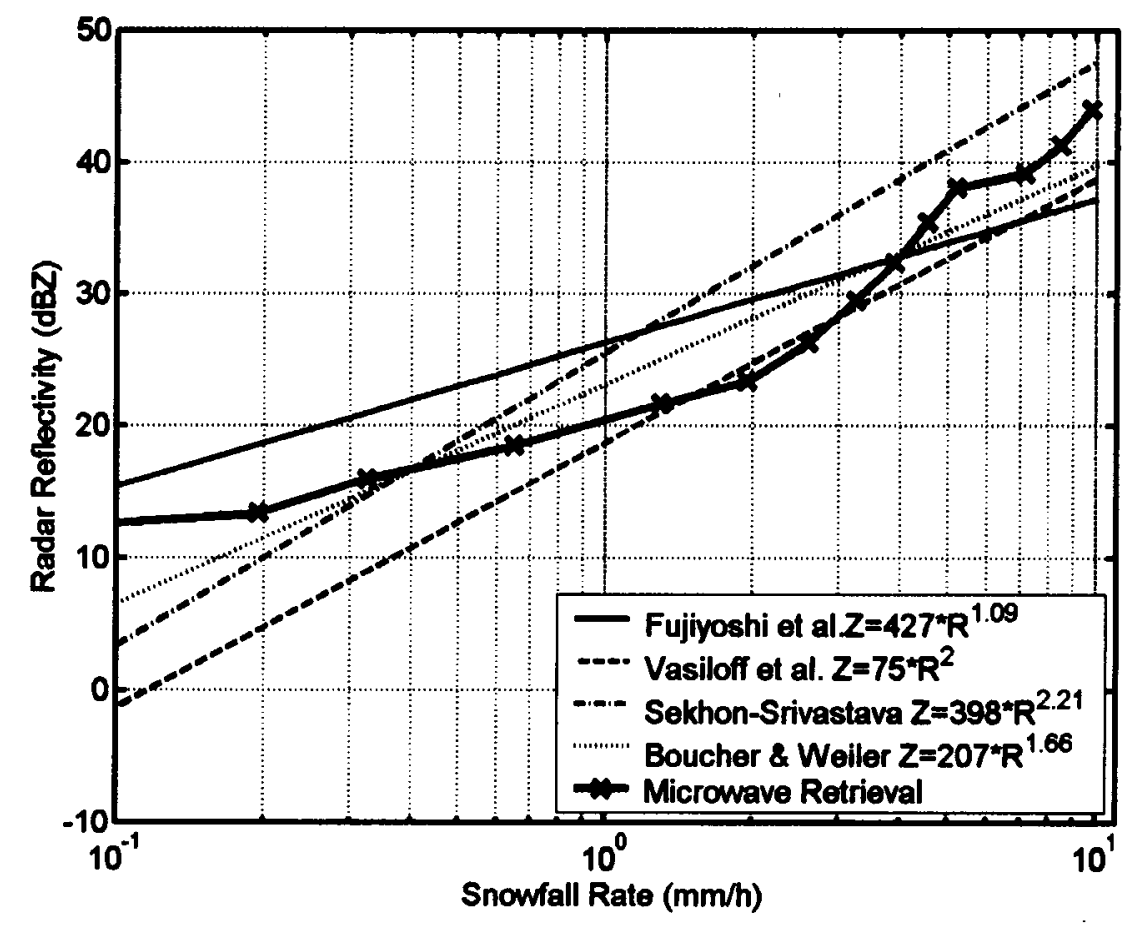

Fig. 6 Measured NWS radar reflectivity, $Z$, versus melted snowfall rate, $R,\left(\mathrm{~mm} \mathrm{~h}^{-1}\right)$ inferred from the $M_{s}(0)\left(-X^{-} X^{-}\right)$. Results are compared to Z-R relationships found by [34]-[37]. 